\title{
Kinetic measurements of the reactivity of hydrogen peroxide and ozone towards small atmospherically relevant aldehydes, ketones and organic acids in aqueous solutions
}

\author{
L. Schöne and H. Herrmann \\ Leibniz Institute for Tropospheric Research (TROPOS), Leipzig, Germany \\ Correspondence to: H. Herrmann (herrmann@ tropos.de) \\ Received: 29 August 2013 - Published in Atmos. Chem. Phys. Discuss.: 7 October 2013 \\ Revised: 21 February 2014 - Accepted: 26 February 2014 - Published: 7 May 2014
}

\begin{abstract}
Free radical reactions are an important degradation process for organic compounds within the aqueous atmospheric environment. Nevertheless, non-radical oxidants such as hydrogen peroxide and ozone also contribute to the degradation and conversion of these substances (Tilgner and Herrmann, 2010). In this work, kinetic investigations of non-radical reactions were conducted using UV/Vis spectroscopy (dual-beam spectrophotometer and stopped flow technique) and a capillary electrophoresis system applying pseudo-first order kinetics to reactions of glyoxal, methylglyoxal, glycolaldehyde, glyoxylic, pyruvic and glycolic acid as well as methacrolein (MACR) and methyl vinyl ketone (MVK) with $\mathrm{H}_{2} \mathrm{O}_{2}$ and ozone at $298 \mathrm{~K}$. The measurements indicate rather small rate constants at room temperature of $k_{2 \text { nd }}<3 \mathrm{M}^{-1} \mathrm{~s}^{-1}$ (except for the unsaturated compounds exposed to ozone). Compared to radical reaction rate constants the values are about 10 orders of magnitude smaller $\left(k_{\mathrm{OH}}\right.$. $\sim 10^{9} \mathrm{M}^{-1} \mathrm{~s}^{-1}$ ). However, when considering the much larger non-radical oxidant concentrations compared to radical concentrations in urban cloud droplets, calculated first-order conversion rate constants change the picture towards $\mathrm{H}_{2} \mathrm{O}_{2}$ reactions becoming more important, especially when compared to the nitrate radical. For some reactions mechanistic suggestions are also given.
\end{abstract}

\section{Introduction}

The troposphere is a complex mixture of gases, liquid substances and particulate constituents (e.g. Herrmann et al., 2010). Some components are emitted primarily into the at- mosphere; others are formed secondarily by chemical or physical processes. Volatile organic compounds (VOCs) are oxidised in the gas phase according to their reactivity, leading to less volatile products. Due to increasing solubility, the uptake to the aqueous phase of cloud or fog droplets or deliquescent particles is enhanced. Especially in atmospheric aerosols, organic compounds account for a large fraction of up to $75 \%$ of the total $\mathrm{PM}_{1}$ mass (Zhang et al., 2007). Regardless of which phase is considered, the main sink for organics in the troposphere is the oxidation by radicals such as $\mathrm{OH}$. (at daytime), or $\mathrm{NO}_{3}$ • (especially at night) and other radicals for the aqueous systems. Therefore, mainly $\mathrm{OH}$. radical photooxidation studies have been conducted in the past concerning the atmospheric transformation of organics. Glyoxal has been subject of several photochemistry studies (e.g. Carlton et al., 2007; Galloway et al., 2011; Zhao et al., 2012); however, carboxylic acids (Charbouillot et al., 2012) such as pyruvic acid (Guzman et al., 2006; Carlton et al., 2006) have also been investigated as well as glycolaldehyde (Beeby et al., 1987; Perri et al., 2009) and the unsaturated compounds methacrolein and methyl vinyl ketone (Liu et al., 2009; Liu et al., 2012). Nevertheless, Tilgner and Herrmann (2010) showed in a scoping study that some non-radical reactions with hydrogen peroxide or ozone and organic accretion reactions like aldol condensation or dimerisation have comparable first-order conversion rate constants to those of $\mathrm{OH} \cdot$ or $\mathrm{NO}_{3} \cdot$. At present, the proper implementation of such processes in models is hindered by the scarcity of kinetic and mechanistic data. Most available kinetic parameters originate from thermodynamical calculations or estimations. 
Table 1. Experimental details.*

\begin{tabular}{|c|c|c|c|c|c|c|c|}
\hline Reactant & Oxidant & $\mathrm{pH}$ & $\begin{array}{l}\text { Method } \\
\& \lambda / \mathrm{nm}\end{array}$ & $\begin{array}{l}\varepsilon \text { (oxidant) at } \\
\lambda / \mathrm{M}^{-1} \mathrm{~cm}^{-1}\end{array}$ & $\begin{array}{l}\varepsilon \text { (reactant) at } \\
\lambda / \mathrm{M}^{-1} \mathrm{~cm}^{-1}\end{array}$ & $\mathrm{c}($ oxidant $) / \mathrm{M}$ & $\mathrm{c}($ reactant $) / \mathrm{M}$ \\
\hline Pyruvic acid & $\mathrm{H}_{2} \mathrm{O}_{2}$ & 1 & $\mathrm{CE}$ & - & - & $0.05-0.25$ & 0.005 \\
\hline Pyruvate & $\mathrm{H}_{2} \mathrm{O}_{2}$ & 7 & $\mathrm{CE}$ & - & - & $0.008-0.024$ & 0.012 \\
\hline Glyoxylic acid & $\mathrm{H}_{2} \mathrm{O}_{2}$ & 1 & $\mathrm{CE}$ & - & - & $0.5-1.5$ & 0.025 \\
\hline Glyoxylate & $\mathrm{H}_{2} \mathrm{O}_{2}$ & 7 & $\mathrm{CE}$ & - & - & $0.03-0.12$ & 0.001 \\
\hline Glycolaldehyde & $\mathrm{H}_{2} \mathrm{O}_{2}$ & 5 & PE 229 & 63.6 & 10.5 & 0.001 & $0.02-0.2$ \\
\hline Glyoxal & $\mathrm{H}_{2} \mathrm{O}_{2}$ & 5 & PE 233 & 54.0 & 0.4 & 0.028 & $0.56-1.68$ \\
\hline Methacrolein & $\mathrm{H}_{2} \mathrm{O}_{2}$ & 5 & SF 310 & 29.8 & 0.5 & 0.02 & $1-3$ \\
\hline Pyruvic acid & $\mathrm{O}_{3}$ & 1 & PE 260 & 3300 & 4.8 & $5 \times 10^{-5}$ & $(1-12.5) \times 10^{-3}$ \\
\hline Pyruvate & $\mathrm{O}_{3}$ & 7 & PE 260 & 3300 & 51.0 & $3 \times 10^{-5}$ & $(0.9-7) \times 10^{-3}$ \\
\hline Glyoxylic acid & $\mathrm{O}_{3}$ & 1 & PE 260 & 3300 & 0.7 & $5 \times 10^{-5}$ & $(0.1-10) \times 10^{-3}$ \\
\hline Glyoxylic acid/glyoxylate & $\mathrm{O}_{3}$ & 3 & PE 260 & 3300 & 1.3 & $5 \times 10^{-5}$ & $(1-7.5) \times 10^{-3}$ \\
\hline Glyoxylate & $\mathrm{O}_{3}$ & 7 & PE 260 & 3300 & 2.1 & $5 \times 10^{-5}$ & $(1-5) \times 10^{-3}$ \\
\hline Glycolic acid & $\mathrm{O}_{3}$ & 1 & PE 260 & 3300 & 0.4 & $5 \times 10^{-5}$ & $(1-37.5) \times 10^{-3}$ \\
\hline Glycolate & $\mathrm{O}_{3}$ & 7 & PE 260 & 3300 & 2.2 & $5 \times 10^{-5}$ & $(1-15) \times 10^{-3}$ \\
\hline Glycolaldehyde & $\mathrm{O}_{3}$ & 5 & PE 260 & 3300 & 34.7 & $5 \times 10^{-5}$ & $(1-15) \times 10^{-3}$ \\
\hline Glyoxal & $\mathrm{O}_{3}$ & 5 & PE 260 & 3300 & 0.3 & $3 \times 10^{-5}$ & $(0.9-3.6) \times 10^{-3}$ \\
\hline Methylglyoxal & $\mathrm{O}_{3}$ & 5 & PE 260 & 3300 & 12.7 & $3 \times 10^{-5}$ & $(0.7-2.1) \times 10^{-3}$ \\
\hline Methacrolein & $\mathrm{O}_{3}$ & 2 & SF 260 & 3300 & 10.0 & $6 \times 10^{-5}$ & $(0.6-1) \times 10^{-4}$ \\
\hline Methyl vinyl ketone & $\mathrm{O}_{3}$ & 2 & SF 260 & 3300 & 7.7 & $6 \times 10^{-5}$ & $(0.6-1) \times 10^{-4}$ \\
\hline
\end{tabular}

* CE = capillary electrophoresis, $\mathrm{PE}=$ Perkin Elmer (dual-beam spectrometer), $\mathrm{SF}=$ stopped flow technique. Path length $=1 \mathrm{~cm}$ for PE and SF, $T=298 \mathrm{~K}$.

The present work aims to improve the lack of kinetic and mechanistic data for reactions of hydrogen peroxide and ozone with organic compounds relevant for the tropospheric multiphase system. Reactants are pyruvic acid/pyruvate, glyoxylic acid/glyoxylate, glycolic acid/glycolate, glycolaldehyde, glyoxal, methylglyoxal, methacrolein and methyl vinyl ketone. Most of the mentioned species are products from the oxidation of isoprene, one of the largest single sources of organic carbon in the troposphere (Guenther et al., 2006; Sharkey et al., 2008). Especially glyoxal and methylglyoxal gained enormous attention in recent studies since they contribute largely to the formation of organic particulate matter (Lim et al., 2013, and references therein). Van Pinxteren et al. (2005) provide cloud water concentrations of glyoxal, methylglyoxal, glycolaldehyde, methacrolein and methyl vinyl ketone measured at a rural site (Mt. Schmücke, Germany) of maximum $88.5,55.8,95.8,0.5$ and $3.1 \mu \mathrm{M}$, respectively. Munger et al. (1990, 1995), Collett et al. (1990) and Matsumoto et al. (2005) state similar values at significant levels. The results from the kinetic investigations are compared to the few available reported values and the atmospheric relevance of the reactions studied is discussed in comparison to model studies.

\section{Experimental}

Table 1 summarises the experimental details of the kinetic investigations. Most measurements were conducted making use of the optical properties of the reacting substances. All measurements were conducted at $298 \mathrm{~K}$. For the acids, the $\mathrm{pH}$ was adjusted to $\mathrm{pH} 1$ and $\mathrm{pH} 8$ to measure both the neutral and anionic form, respectively. For the aldehydes, no $\mathrm{pH}-$ altering substances were added, resulting in values of $\mathrm{pH} 4.5$ to 5.5 .

\subsection{Studies of ozone reactions}

Pseudo-first order kinetics were applied for the ozone investigations using a dual-beam UV/Vis spectrophotometer (LAMBDA 900, Perkin Elmer). Consequently, the reactants' concentrations were held in excess over the ozone concentration (see Eq. 2). The depletion of ozone was recorded with time by tracking its absorbance at $\lambda=260 \mathrm{~nm}$ $\left(\varepsilon=3300 \mathrm{M}^{-1} \mathrm{~cm}^{-1}\right.$, Hart et al., 1983). The initial reactant concentrations were chosen to be $(7-22) \times 10^{-4} \mathrm{M}$, depending on the spectral conditions between reactant and oxidant, and $c_{0}\left(\mathrm{O}_{3}\right)=5 \times 10^{-5} \mathrm{M}$, respectively. As a reaction vessel, a $3.2 \mathrm{ml}$ sealed fused silica cuvette $(d=1 \mathrm{~cm})$ was used. Measurements with the dual-beam spectrometer lasted a minimum of $5 \mathrm{~min}$ to several hours, with reactant mixing times of about $5 \mathrm{~s}$ because of manual pipetting. This very short mixing time is considered affordable given the very slow reaction rates.

The stopped flow technique was used (SF-61DX2, HITECH Scientific, UV / Vis detection) for faster reactions with unsaturated compounds like methacrolein and methyl vinyl ketone. The advantage of this method is the immediate start 
of the absorbance recording in the moment of reactant mixing. The mixing time of the stopped flow technique is about $1 \mathrm{~ms}$. As the measurement of an ozone reaction with an unsaturated compound lasted a minimum of $1 \mathrm{~s}$, only the first data point $(t=1.48 \mathrm{~ms})$ was discarded a priori. There was no deviation in linearity observed at the beginning of recording. Here, the concentration of ozone was also monitored at $\lambda=260 \mathrm{~nm}$ during the reaction, with initial concentrations of MACR and MVK being $(0.6-1) \times 10^{-4} \mathrm{mM}$ and $\mathrm{c}_{0}\left(\mathrm{O}_{3}\right)=6 \times 10^{-6} \mathrm{M}$, respectively. The $\mathrm{pH}$ was adjusted to $\mathrm{pH}$ 2. From the concentration-time profiles measured, pseudo-first order rate constants $k_{1 \mathrm{st}}\left(\mathrm{s}^{-1}\right)$ can be obtained according to Eq. (3). Variation of the initial concentration of the reactant in excess enables calculation of the second-order rate constant $k_{2 \text { nd }}\left(\mathrm{M}^{-1} \mathrm{~s}^{-1}\right.$, Eq. 2).

$\mathrm{O}_{3}+\mathrm{X} \rightarrow$ products

$\frac{d c\left(\mathrm{O}_{3}\right)}{d t}=-k_{2 \mathrm{nd}} \cdot c\left(\mathrm{O}_{3}\right) \cdot c(X)$

$k_{1 \mathrm{st}}=k_{2 \mathrm{nd}} \cdot c\left(\mathrm{O}_{3}\right) \quad$ if $c(X) \gg c\left(\mathrm{O}_{3}\right)$

$\frac{d c\left(\mathrm{O}_{3}\right)}{d t}=-k_{1 \mathrm{st}} \cdot c\left(\mathrm{O}_{3}\right)$

Ozone was produced using the ozone generator $500 \mathrm{M}$ (Fischer, Germany) with pure $\mathrm{O}_{2}$ from a gas cylinder. Ozone "stock solutions" were prepared by introducing this ozoneenriched gas flow to an aqueous solution with an adjusted $\mathrm{pH}$ value. Ozone "stock solutions" were prepared freshly prior to each experiment as it decomposes in an aqueous solution (see Reactions R2 to R5). The ozone concentration in the "stock solution" was determined spectroscopically at $260 \mathrm{~nm}$ using the extinction coefficient by Hart et al. (1983). Subsequently, the stock solution was diluted to the requested concentration. The time between the end of bubbling and the start of the measurement was about one minute. Throughout the experiments with the dual-beam spectrometer, the decay of the ozone concentration was recorded simultaneously in the reference beam path in order to obtain the ozone decay solely resulting from the reaction with the organic compound.

\subsection{Studies of $\mathrm{H}_{2} \mathrm{O}_{2}$ reactions}

The reactions of $\mathrm{H}_{2} \mathrm{O}_{2}$ with the target reactants proceeded slowly enough to allow manual pipetting to mix reactant aliquots and start the reaction while recording the time with a stopwatch. Total volumes were $25 \mathrm{ml} ; 0.3 \mathrm{ml}$ volume samples were withdrawn at time intervals from $10 \mathrm{~s}$ up to some minutes. In cases where the UV/Vis spectra of $\mathrm{H}_{2} \mathrm{O}_{2}$ and the respective reactant showed appreciable differences without interfering absorptions in certain wavelength ranges, these reactions were kinetically investigated using UV/Vis spectroscopy. Pyruvic acid / pyruvate and glyoxylic acid / glyoxylate were quantified by capillary electrophoresis
(CE) because of an overlap of their UV spectrum with that of $\mathrm{H}_{2} \mathrm{O}_{2}$ making a kinetic analysis using UV spectroscopy impossible. The reaction was simply stopped by adding $3 \mathrm{ml}$ of catalase stock solution to each sample $(0.3 \mathrm{ml})$. The stock solution was prepared by solving $400 \mu \mathrm{l}$ of catalase in $50 \mathrm{ml}$ MilliQ water. According to the product information, catalase acts as catalyst in the following two-step reaction: $2 \mathrm{H}_{2} \mathrm{O}_{2} \rightarrow \mathrm{O}_{2}+2 \mathrm{H}_{2} \mathrm{O}$. In the first step, $\mathrm{H}_{2} \mathrm{O}_{2}$ is reduced und the enzyme is oxidised yielding water as product. In the second step, $\mathrm{H}_{2} \mathrm{O}_{2}$ as well as the previously oxidised enzyme get reduced, leading to water and $\mathrm{O}_{2}$ as products. How fast the reaction occurs, depends on the concentration of catalase and $\mathrm{H}_{2} \mathrm{O}_{2}$, being highest at high concentrations (MichaelisMenten theory). During the conducted experiments both concentrations were comparably high (e.g. $\left.\mathrm{c}\left(\mathrm{H}_{2} \mathrm{O}_{2}\right)=1 \mathrm{M}\right)$, thus the reaction of $\mathrm{H}_{2} \mathrm{O}_{2}$ with catalase is much faster than with the reactant. The rate constant of $\mathrm{H}_{2} \mathrm{O}_{2}+$ catalase was reported with $k_{2 \text { nd }}=2 \times 10^{7} \mathrm{M}^{-1} \mathrm{~s}^{-1}$ (Ogura, 1955). Tests revealed that the amount of catalase was sufficient to destroy $\mathrm{H}_{2} \mathrm{O}_{2}$ and stop the reaction with the organic acid (= reactant). This was concluded as no change in the concentration of the formed organic acids was observed over a period of a week after the reaction was stopped.

During CE measurements two buffer reservoirs are constantly filled with an electrolyte containing $2 \mathrm{mM}$ 5-sulfosalicylic acid, $8 \mathrm{mM}$ tris(hydroxylmethyl)aminomethane and $\quad 0.001 \%$ hexadimethrin bromide at $\mathrm{pH}$ 8.2. The reservoirs are connected by a fused silica capillary $(82 \mathrm{~cm})$ with an inner diameter of $75 \mu \mathrm{m}$. A high voltage source is adjusted at $30 \mathrm{kV}$. Due to the electrolyte $\mathrm{pH}$ of 8.2 organic acids in the sample deprotonate and the so formed anionic compounds move towards the cathode, the migration speed depending on their size and charge. The detection was performed indirectly at $\lambda=208 \mathrm{~nm}$ (for details see ESM). Concentration-time profiles of the corresponding acid have been obtained and the kinetic data analysis occurs analogously to the ozone measurements. The CE also provides information of the products formed during the reaction.

As pseudo-first order conditions were applied, the reactant, whose concentration would not be recorded, was added in excess in order to keep its concentration constant during the measurements. For CE measurements the oxidant was in excess just as for methacrolein $+\mathrm{H}_{2} \mathrm{O}_{2}$ (because the acids and methacrolein were analysed), whereas the reactions of $\mathrm{H}_{2} \mathrm{O}_{2}$ with glycolaldehyde and glyoxal were conducted under aldehyde excess (where $\mathrm{H}_{2} \mathrm{O}_{2}$ was analysed). All experimental parameters are summarised in Table 1.

\subsection{Chemicals}

The following chemicals were used without further purification: ammonium sulfate ( $>99 \%$, Riedel deHaën), sodium pyruvate $(99 \%$, Merck), sodium phosphate dibasic dihydrate (>98\%, Fluka), glycolaldehyde dimer (mixture from 
stereoisomers, Aldrich), glycolic acid ( $\geq 99 \%$, Fluka), glyoxal (40\% in water, Sigma Aldrich), glyoxylic acid monohydrate ( $\geq 97 \%$, Fluka), hexadimethrin bromide (HDB, $\geq 95 \%$, Sigma Aldrich), catalase (from bovine liver, aqueous suspension, Sigma), methacrolein (95\%, Aldrich), methylglyoxal (47\% in water, Sigma), methyl vinyl ketone (99\%, Aldrich), sodium phosphate monobasic (99\%, Riedel deHaën), perchloric acid (70-72\%, J. T. Baker), phosphoric acid (85\%, Aldrich), oxygen (Premium), 5 sulfosalicylic acid (for electrophoresis, Sigma Aldrich), tertbutanol (99.7\%, Fluka), tris(hydroxymethyl)aminomethane ( $\geq 99.9 \%$, Sigma Aldrich), hydrogen peroxide ( $\geq 30 \%$ in water, Fluka). All solutions were freshly prepared with MilliQ water $\left(18 \mathrm{M} \Omega \mathrm{cm}^{-1}\right)$. The $\mathrm{pH}$ was adjusted using a phosphate buffer system or perchloric acid.

\section{Results and discussion}

\subsection{Ozone measurements}

The ozone measurements were tested applying the system suggested by Hoigné and Bader (1983b) with tert-butanol as $\mathrm{OH}$ - scavenger. In an aqueous solution, ozone will degrade to form hydroperoxyl radicals $\mathrm{HO}_{2}$ • or hydroperoxide anions $\mathrm{HO}_{2}^{-}$(Reactions R2 and R3) as well as oxygen or superoxide, respectively, as a consequence of its reaction with hydroxide ions. The initial involvement of hydroxide causes a dependence of this reaction on the $\mathrm{pH}$. Since $\mathrm{HO}_{2}$ - is a quite reactive species, it reduces ozone forming even more reactive $\mathrm{OH} \cdot$ radicals (Reaction R4). These will destroy ozone, leading again to $\mathrm{HO}_{2}$ • (Reaction R5). Taking $\mathrm{OH}$ • off the system by addition of a scavenger (R6) means preventing $\mathrm{O}_{3}$ from being destroyed by the following cycle.

$\mathrm{O}_{3}+\mathrm{OH}^{-} \rightarrow \mathrm{O}_{2}^{-}+\mathrm{HO}_{2} \cdot \quad k=210 \mathrm{M}^{-1} \mathrm{~s}^{-1}$

(Staehelin and Hoigné, 1982)

$\mathrm{O}_{3}+\mathrm{OH}^{-} \rightarrow \mathrm{O}_{2}+\mathrm{HO}_{2}^{-} \quad k=40 \mathrm{M}^{-1} \mathrm{~s}^{-1}$

(Sehested et al., 1991)

$\mathrm{O}_{3}+\mathrm{HO}_{2} \cdot \rightarrow 2 \mathrm{O}_{2}+\mathrm{OH} . \quad k<10^{4} \mathrm{M}^{-1} \mathrm{~s}^{-1}$

(Sehested et al., 1984)

$\mathrm{O}_{3}+\mathrm{OH} \bullet \rightarrow \mathrm{O}_{2}+\mathrm{HO}_{2} \cdot \quad k=1.1 \times 10^{8} \mathrm{M}^{-1} \mathrm{~s}^{-1}$

(Sehested et al., 1984)

$\mathrm{OH} \cdot+t-\mathrm{BuOH} \rightarrow$ products $\quad k=6 \times 10^{8} \mathrm{M}^{-1} \mathrm{~s}^{-1}$

(Buxton et al., 1988)

Additionally, the $\mathrm{pH}$ of the aqueous solution can be adjusted to an acidic milieu (e.g. $\mathrm{pH} 2$ ) to slow down the rate of Reaction (R2) and suppress ozone decomposition.

Hoigné and Bader tested several $\mathrm{OH}$ - radical scavenging substances such as $\mathrm{HCO}_{3}^{-}, \mathrm{PrOH}, \mathrm{BuOH}, \mathrm{NaHCO}_{3}$ or methyl mercury hydroxide, respectively, but $t-\mathrm{BuOH}$ was
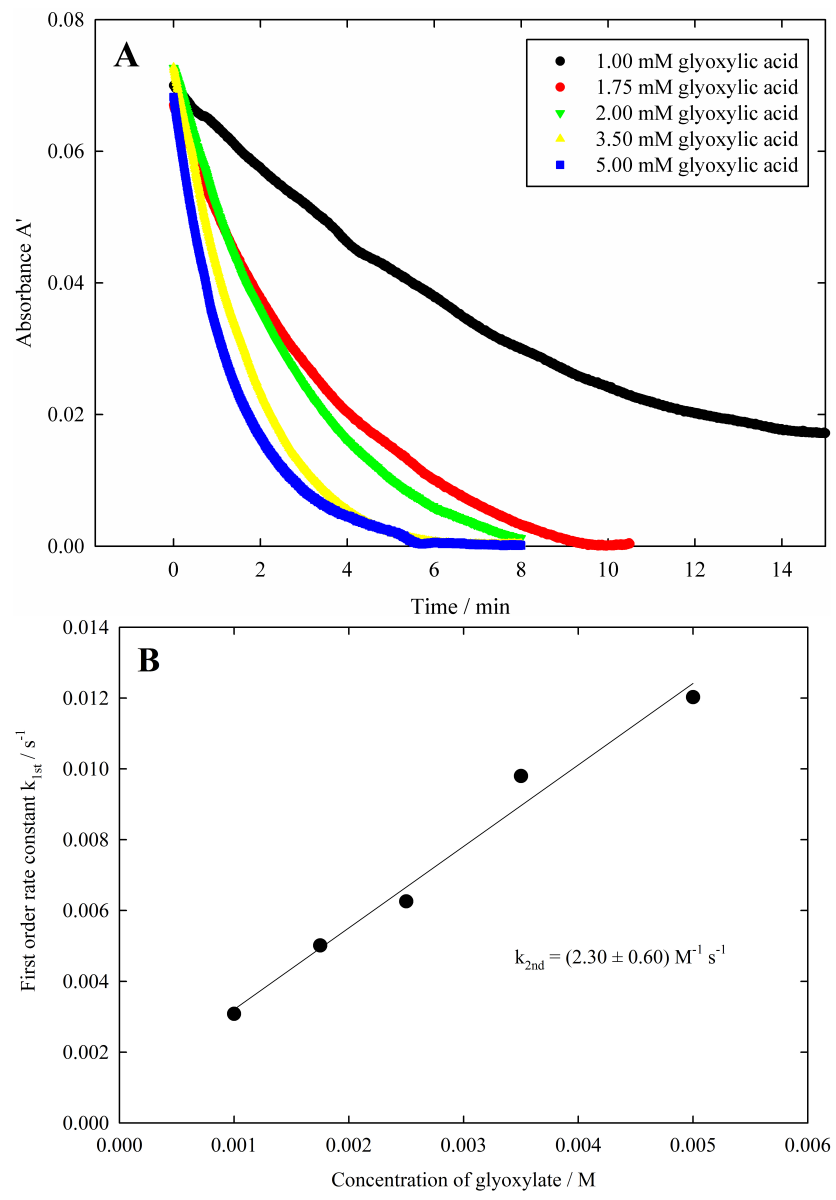

Fig. 1. (A) Absorbance-time profiles of ozone during the reaction with glyoxylate at $\mathrm{pH} 7$. The initial concentration of ozone was about $\mathrm{c}\left(\mathrm{O}_{3}\right)=5 \times 10^{-5} \mathrm{M}$. (B) Pseudo-first order rate constants $k_{1 \mathrm{st}}$ plotted over the concentration of glyoxylate.

found to be the most appropriate scavenger (Hoigné and Bader, 1983a, b, 1985). Variation of $t-\mathrm{BuOH}$ beyond the suggested concentration led to a significantly smaller $\mathrm{S} / \mathrm{N}$ ratio but showed no change in the results. Therefore, the proposed concentration of $15 \mathrm{mM} t-\mathrm{BuOH}$ was adopted within all ozone measurements, also in the present study.

\subsubsection{Monocarboxylic acids + ozone}

Figure 1 shows the absorbance vs. time (left) and $k_{1 s t}$ vs. $\mathrm{c}$ (glyoxylate) (right) plots for the reaction of glyoxylate with $\mathrm{O}_{3}$ at $\mathrm{pH} 7$ measured with the UV spectrometer. The pseudofirst order rate constant $k_{1 s t}$ increases with increasing glyoxylate concentration, the slope corresponds to the secondorder rate constant $k_{\text {glyoxylate }}=2.30 \pm 0.60 \mathrm{M}^{-1} \mathrm{~s}^{-1}$.

The reaction of glyoxylic acid / glyoxylate with ozone was studied at three different $\mathrm{pH}$ values to obtain a direct comparison to the work of Hoigné and Bader (1983b). Figure 2 shows the $\mathrm{pH}$-dependent second-order rate constants from this work (black dots) and from Hoigné and Bader (1983b, 
Table 2. Second-order rate constants $\left[\mathrm{M}^{-1} \mathrm{~s}^{-1}\right]$ for the investigated systems. The uncertainties stated are statistical errors with the student $t$ factor for the $95 \%$ confidence level derived from linear regression analysis.

\begin{tabular}{lll}
\hline & \multicolumn{2}{c}{$\mathrm{k}_{2 \mathrm{nd}} / \mathrm{M}^{-1} \mathrm{~s}^{-1}$} \\
Substance & $\mathrm{H}_{2} \mathrm{O}_{2}$ & $\mathrm{O}_{3}$ \\
\hline Glyoxylic acid pH 1 & $(3.96 \pm 0.91) \times 10^{-3}$ & $0.14 \pm 0.06$ \\
Glyoxylic acid / glyoxylate pH 3 & - & $0.53 \pm 0.12$ \\
Glyoxylate pH 7 & $0.11 \pm 0.01$ & $2.30 \pm 0.60$ \\
Pyruvic acid pH 1 & $0.12 \pm 0.04$ & $0.13 \pm 0.03$ \\
Pyruvate pH 7 & $0.75 \pm 0.16$ & $0.98 \pm 0.35$ \\
Glycolic acid pH 1 & - & $(5.50 \pm 1.52) \times 10^{-2}$ \\
Glycolate pH 7 & - & $0.71 \pm 0.05$ \\
Glycolaldehyde pH 5 & $0.04 \pm 0.02$ & $0.52 \pm 0.10$ \\
Glyoxal pH 5 & $(1.67 \pm 0.80) \times 10^{-4}$ & $0.90 \pm 0.17$ \\
Methylglyoxal pH 5 & - & $2.89 \pm 0.72$ \\
Methacrolein pH 2 & $(7.56 \pm 2.84) \times 10^{-2}$ & $(2.25 \pm 0.53) \times 10^{4}$ \\
Methyl vinyl ketone pH 2 & - & $(7.11 \pm 1.06) \times 10^{4}$ \\
\hline
\end{tabular}

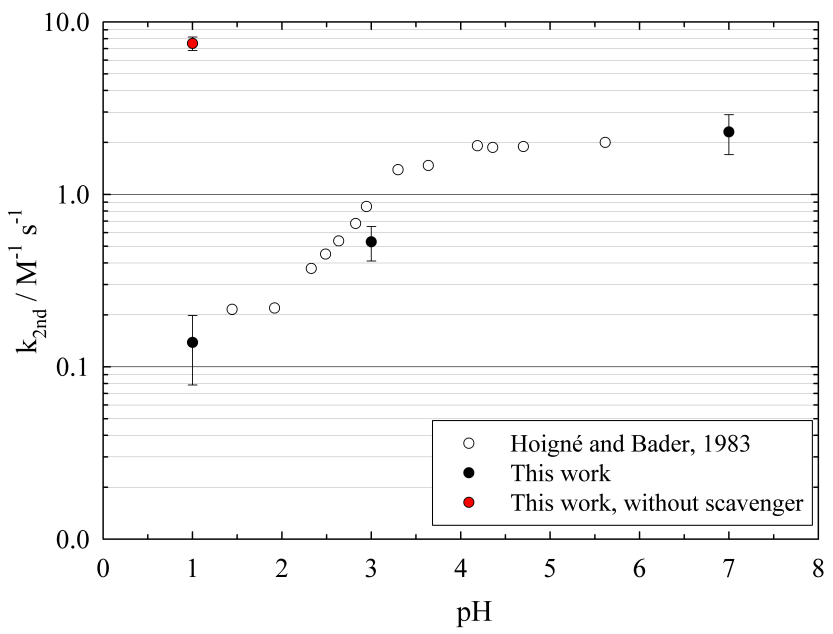

Fig. 2. Rate constants $\left[\mathrm{M}^{-1} \mathrm{~s}^{-1}\right]$ plotted as a function of $\mathrm{pH}$ value for the reaction of glyoxylic acid/glyoxylate with ozone. Hoigné and Bader (1983b; white dots); this work (black dots); no scavenger used in this work (red dot).

white dots). The figure indicates good agreement between both studies.

Figure 2 furthermore includes one data point measured during this study at $\mathrm{pH} 1$ where no scavenger was added to the solution (red dot). The resulting rate constant is highly overestimated due to the additional reduction of ozone by reactions with $\mathrm{OH}$ - (see Reaction R5). Adding a scavenger is therefore essential if reactions with ozone are investigated.

Hoigné and Bader do not suggest a reaction pathway of glyoxylic acid and ozone. Scheme 1 illustrates one tentative mechanism which is proposed here. In solution, most of the aldehyde group in glyoxylic acid is hydrated $\left(\mathrm{K}_{\text {hydr }}=1.09 \times 10^{4} \mathrm{M} \mathrm{atm}^{-1}\right.$, Ip et al., 2009). With ozone in the system, the most weakly bound $\mathrm{H}$ atom at the carbon atom $\left(\mathrm{BDE}=337.2 \mathrm{~kJ} \mathrm{~mol}^{-1}\right.$, Dean and Lange, 1992) is abstracted, leading to an $\mathrm{OH} \cdot$ radical from the decomposition of $\mathrm{HO}_{3}$, molecular oxygen and an alkyl radical (3). This step is identical with the one proposed by Caprio et al. (1987). Holen et al. (1998) also suggest an $\mathrm{H}$ atom abstraction as well as the addition of ozone to the $\mathrm{C}=\mathrm{O}$ double bond that can be neglected as glyoxylic acid is hydrated in solution. Subsequent reaction with the released $\mathrm{O}_{2}$ forms a peroxyl radical (4) which quickly decomposes to form oxalic acid (5) and an $\mathrm{HO}_{2}$ - radical. Caprio et al. (1987) and Holen et al. (1998) also identified oxalic acid as a product during the reaction of glyoxylic acid with ozone. This reaction can therefore be regarded as an additional reaction pathway to form oxalic acid which is the most abundant diacid in aqueous atmospheric environments (Myriokefalitakis et al., 2011). Nevertheless, it has to be noted that there were no product studies conducted within this work. Thus, the proposed mechanism is tentative.

The additional formation of $\mathrm{OH} \cdot$ and $\mathrm{HO}_{2}$ - radicals during this reaction makes it necessary to add a scavenger to the reacting system. Additionally, Caprio et al. (1987) state a much larger second-order rate constant of $k_{\text {glyoxylic acid }+\mathrm{O}_{3}}=(20 \pm 0.5) \mathrm{M}^{-1} \mathrm{~s}^{-1}$. The reasons for this discrepancy are the missing scavenger during their measurements and probably a different ratio of protonated and deprononated acid forms since no $\mathrm{pH}$ value was declared.

The reaction of glycolic acid with ozone also leads, analogously to the mechanism just proposed, to the formation of glyoxylic acid and $\mathrm{HO}_{2} \cdot$. The rate constants measured here is $k_{\text {glycolic acid }+\mathrm{O}_{3}}=(5.50 \pm 1.52) \times 10^{-2} \mathrm{M}^{-1} \mathrm{~s}^{-1}$.

For the interaction of pyruvic acid with ozone no mechanism is proposed so far in the literature. The only suggestions include manganese as a catalyst, leading to acetic acid as well as $\mathrm{O}_{2}$ and $\mathrm{CO}_{2}(\mathrm{pH}$ 2-4, Andreozzi et al., 1998). The rate constant measured in this work is $k_{\text {pyruvic acid }+\mathrm{O}_{3}}=(0.13 \pm 0.03) \mathrm{M}^{-1} \mathrm{~s}^{-1}$. Table 2 indicates a 


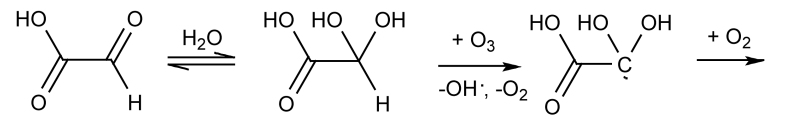

(1)
(2)
(3)

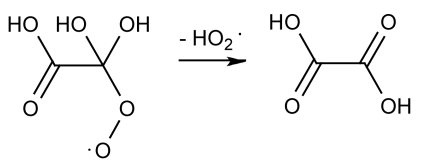

(4)

(5)

Scheme 1. Proposed oxidation mechanism of (hydrated) glyoxylic acid exposed to ozone in an aqueous environment.

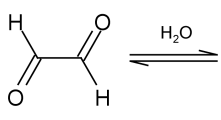

(1)

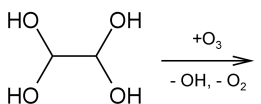

(2)<smiles>O[C+](O)C(O)O</smiles>

(3)

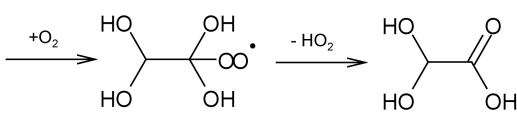

(4)
(5)

Scheme 2. Reaction mechanism for fully hydrated glyoxal reacting with ozone.

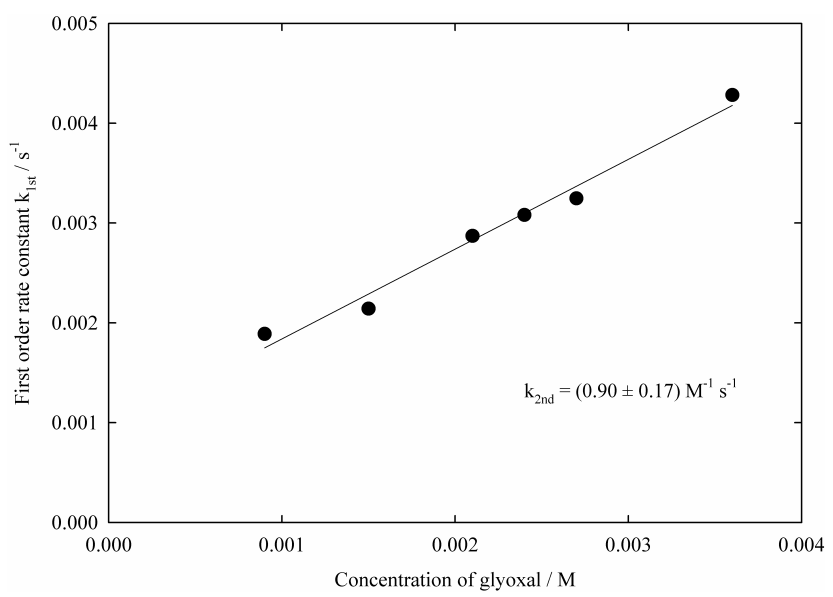

Fig. 3. Pseudo-first order rate constants $k_{1 \text { st }}$ plotted over the concentration of glyoxal during the reaction with ozone at $\mathrm{pH}$ 5. The initial concentration of ozone was about $\mathrm{c}\left(\mathrm{O}_{3}\right)=3 \times 10^{-5} \mathrm{M}$. The slope corresponds to $k_{\text {glyoxal }+\mathrm{O}_{3}}=(0.90 \pm 0.17) \mathrm{M}^{-1} \mathrm{~s}^{-1}$.

higher reactivity of the deprotonated form of the acid compared to the protonated form by about one order of magnitude. The reason for this could be the stronger electronwithdrawing properties of the deprotonated carboxylate group, leading to different BDEs and therefore a more easily abstractable hydrogen at the neighbouring $\mathrm{C}$ atom.

\subsubsection{Aldehydes + ozone}

Figure 3 shows the dependence of the pseudo-first order rate constant on the glyoxal concentration during the reaction with ozone, which corresponds to a second-order rate constant of $k_{\text {glyoxal }+\mathrm{O}_{3}}=(0.90 \pm 0.17) \mathrm{M}^{-1} \mathrm{~s}^{-1}$. The other two aldehydes, methylglyoxal and glycolaldehyde, react with similar rate constants of $k_{\text {methylglyoxal }+\mathrm{O}_{3}}=(2.89 \pm 0.72)$ $\mathrm{M}^{-1} \mathrm{~s}^{-1}$ and $k_{\text {glycolaldehyde }}+\mathrm{O}_{3}=(0.52 \pm 0.10) \mathrm{M}^{-1} \mathrm{~s}^{-1}$, respectively. The reactivities of the deprotonated forms of the acids are also in the same range (see Table 2).

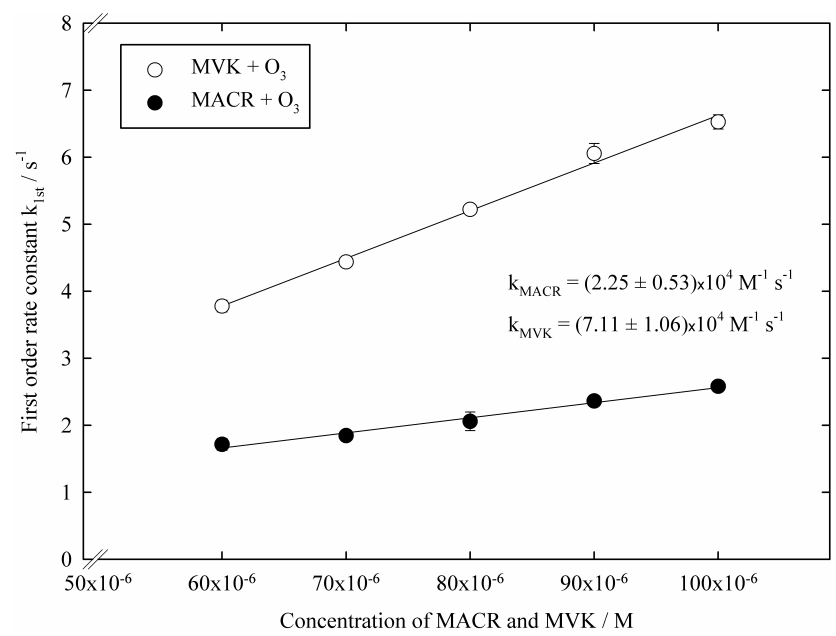

Fig. 4. Pseudo-first order rate constants $k_{1 \text { st }}$ plotted over the concentration of methacrolein and methyl vinyl ketone for the reaction with ozone at $\mathrm{pH} 2$. The initial concentration of ozone was about $\mathrm{c}\left(\mathrm{O}_{3}\right)=6 \times 10^{-6} \mathrm{M}$.

Since the given rate constants are first determinations (at least under these temperature conditions, namely $T=298 \mathrm{~K}$ ), no appropriate comparison is possible. Ervens et al. (2004) state that glyoxal is present in the geminal diol form due to its high hydration constant in the aqueous phase $\left(\mathrm{K}_{\mathrm{hydr}}=3 \times 10^{5} \mathrm{M}^{-1}\right.$, Betterton and Hoffmann, 1988). The proposed mechanism in Scheme 2 was developed following the one of glyoxylic acid + ozone (Scheme 1).

At first, hydrogen abstraction at the $\mathrm{C}-\mathrm{H}$ bond of the aldehyde group (3) occurs which was also proposed by Voukides et al. (2009). Subsequently, the addition of oxygen forming a peroxyl radical (4) and $\mathrm{HO}_{2}$ elimination leads to hydrated glyoxylic acid as main stable oxidation product (5). Caprio et al. (1987) have proposed the reaction of the (unhydrated) alkyl radical with ozone instead of oxygen. This pathway is not very likely because of the excess of $\mathrm{O}_{2}$ over $\mathrm{O}_{3}$ which they explicitly stated in their study. After another reaction of the so formed alkoxy radical with another (unhydrated) 
glyoxal molecule, which appears improbable, also glyoxylic acid is formed (Caprio et al., 1987). As it has been known since the work of von Sonntag and Schuchmann (1991) that $\alpha$-hydroxy-peroxyl radicals likely eliminate $\mathrm{HO}_{2}$ rather than abstract a hydrogen atom, the mechanism of Caprio et al (1987) does not appear feasible.

With regards to the reactions of methylglyoxal and glycolaldehyde with ozone, no reaction mechanism can be given due to missing analytical data since no product studies were performed in this work.

\subsubsection{Unsaturated compounds + ozone}

The reactions of methacrolein (MACR) and methyl vinyl ketone (MVK) with ozone were investigated using the stopped flow technique at $\mathrm{pH} 2$. These more complex measurements were necessary because of the much higher reactivity of ozone towards unsaturated compounds as ozone adds to $\mathrm{C}-\mathrm{C}$ double bonds. As can be seen from Fig. 4, reactions between MACR or MVK and ozone are at least 4 orders of magnitude faster than the other investigated substances (see also Table 2). The second-order rate constants determined in this study are $k_{\mathrm{MACR}+\mathrm{O}_{3}}=(2.25 \pm 0.53) \times 10^{4} \mathrm{M}^{-1} \mathrm{~s}^{-1}$ and $k_{\mathrm{MVK}+\mathrm{O}_{3}}=(7.11 \pm 1.06) \times 10^{4} \mathrm{M}^{-1} \mathrm{~s}^{-1}$, respectively.

Pedersen and Sehested (2001) also studied both reactions ( $\mathrm{pH}$ 2) and observed quite similar rate constants. These authors obtained values of $k_{\mathrm{MACR}+\mathrm{O}_{3}}=(2.4 \pm 0.1) \times 10^{4} \mathrm{M}^{-1} \mathrm{~s}^{-1}$ and $\left.k_{\mathrm{MVK}+\mathrm{O}_{3}}=(4.4 \pm 0.2) \times 10^{4} \mathrm{M}^{-1} \mathrm{~s}^{-1}\right)$ for the reaction with MACR and MVK, respectively. These values indicate good agreement with this work's measurements. For the reaction of MVK with ozone a 1.6 times larger rate constant was observed in this work.

The mechanism for the reaction of MACR and MVK with ozone is provided by Chen et al. (2008). Addition of ozone to each of the molecules builds primary ozonides which decompose rapidly to $\mathrm{HCHO}$, methylglyoxal and several Criegee intermediates. These reactive intermediates get deactivated by collision, become hydrolysed and decompose to $\mathrm{HCHO}$ and methylglyoxal, but $\mathrm{H}_{2} \mathrm{O}_{2}$ and pyruvic acid are also formed. Ervens et al. (2004) confirm the formation of $\mathrm{HCHO}$ and methylglyoxal and also provide ratios for each pathway. The reaction of ozone with unsaturated compounds therefore provides an effective way to build up organic aldehydes and acids in the atmospheric aqueous phase.

\section{2 $\quad \mathrm{H}_{2} \mathrm{O}_{2}$ measurements}

\subsubsection{Monocarboxylic acids $+\mathrm{H}_{2} \mathrm{O}_{2}$}

Reactions of pyruvic acid and glyoxylic acid (and their anions) with $\mathrm{H}_{2} \mathrm{O}_{2}$ were investigated using the capillary electrophoresis system. Hence, not only concentration-time profiles of the reacting acid were obtained, but the formation of anionic reaction products was also observed.
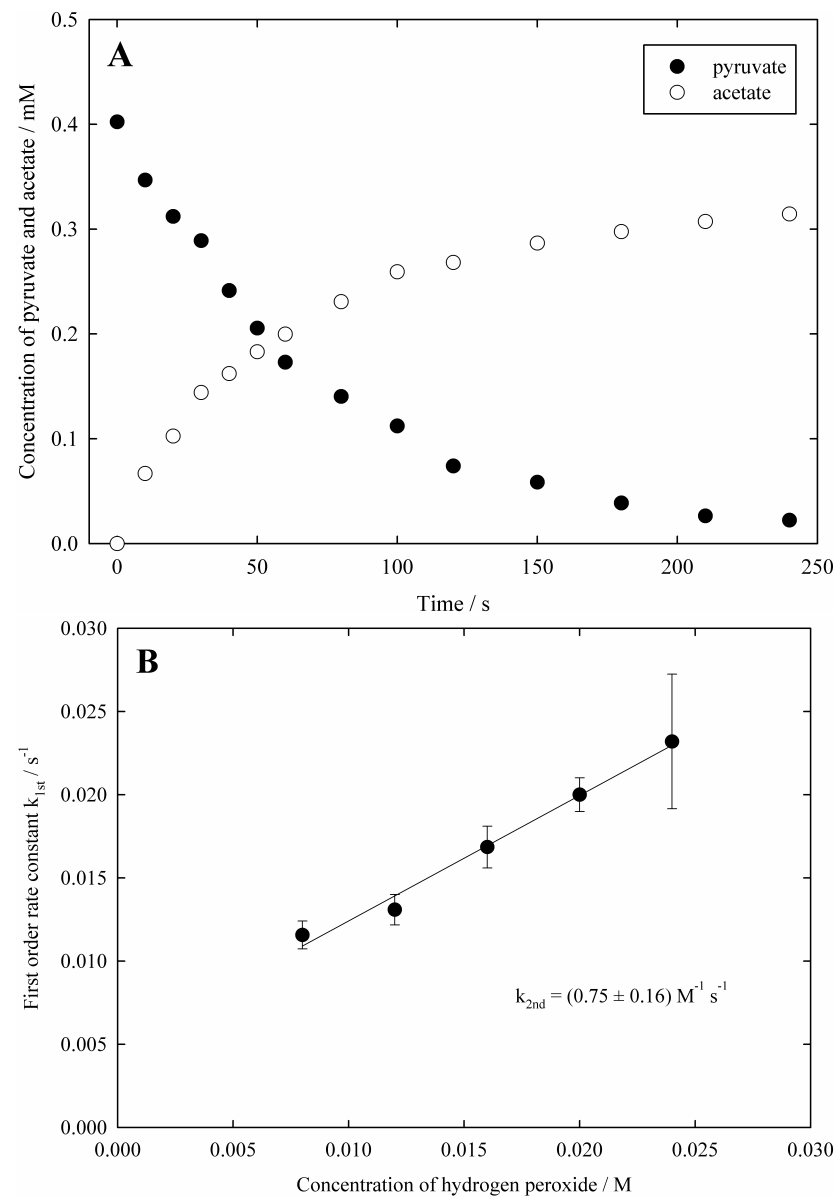

Fig. 5. (A) Concentration-time profiles of pyruvate and acetate during the reaction with $\mathrm{H}_{2} \mathrm{O}_{2}$ at $\mathrm{pH} 7$ for $\mathrm{c}$ (pyruvate $)=0.4 \mathrm{mM}$ and $\mathrm{c}\left(\mathrm{H}_{2} \mathrm{O}_{2}\right)=12 \mathrm{mM}$. (B) Pseudo-first order rate constants $k_{1 \text { st }}$ plotted over the concentration of hydrogen peroxide for the reaction with pyruvate at $\mathrm{pH} 7$.

Figure 5 shows on the left hand side the track of the pyruvate depletion as well as the development of acetate during the reaction of pyruvate with hydrogen peroxide. Until 50 seconds reaction time, one depleted molecule of pyruvate leads to one formed molecule of acetate. In the further course of the reaction the sum of both educt and product is not constant anymore. A reason could be the formation of other products than acetic acid which cannot be detected by capillary electrophoresis.

von Sonntag and Schuchmann (1997) and Stefan and Bolton (1999) propose mechanisms which agree with our observations, thus acetate must be the main oxidation product of this reaction (see Scheme 3).

The rate constants determined in this work can only be compared with a single value by Stefan and Bolton (1999) (see Table 3). Concentrations of pyruvate and hydrogen peroxide as well as replicates undertaken exceed those from Stefan and Bolton (1999). Also, the determined rate constant is 
Table 3. Comparison of this work's reaction conditions with Stefan and Bolton's (1999).

\begin{tabular}{lccc}
\hline & \multicolumn{2}{c}{ This work } & Stefan and Bolton (1999) \\
\hline Method & \multicolumn{2}{c}{ Capillary electrophoresis } & Ion exchange chromatography \\
$\mathrm{pH}$ & 1 & 7 & "mostly ionised" \\
$\mathrm{c}($ pyruvate $) / \mathrm{mM}$ & 5 & 0.4 & 0.25 \\
$\mathrm{c}\left(\mathrm{H}_{2} \mathrm{O}_{2}\right) / \mathrm{mM}$ & $50-150$ & $8-24$ & 5 \\
$\mathrm{c}\left(\mathrm{H}_{2} \mathrm{O}_{2}\right) / \mathrm{c}($ pyruvate $)$ & $10-30$ & $30-60$ & 20 \\
no. of $\mathrm{c}\left(\mathrm{H}_{2} \mathrm{O}_{2}\right)$ & 5 & 5 & 1 \\
$k_{2 \text { nd }} / \mathrm{M}^{-1} \mathrm{~s}^{-1}$ & $0.12 \pm 0.04$ & $0.75 \pm 0.16$ & 0.11 \\
\hline
\end{tabular}

larger in this work. Furthermore, Stefan and Bolton (1999) do not specify any exact $\mathrm{pH}$ value; they solely write that pyruvate is "mostly present in its ionised form". Since $99.99 \%$ of the acid is ionised at $\mathrm{pH} 7$, the working $\mathrm{pH}$ of Stefan and Bolton (1999) must be smaller than pH 7. This could be an indication for the smaller $k_{2 n d}$ value these authors observed. We used a phosphate buffer system to adjust the $\mathrm{pH}$, which could be a potential source of impurities leading to a higher rate constant. However, control experiments provided evidence that the buffer system used does not disturb the measurement.

The reactivity of glyoxylic acid and glyoxylate towards $\mathrm{H}_{2} \mathrm{O}_{2}$ is about one to two orders of magnitude smaller compared to pyruvic acid/pyruvate (see Table 2). The rate constants determined are $k_{\text {glyoxylic acid }+\mathrm{H}_{2} \mathrm{O}_{2}}=(3.96 \pm 0.91) \times 10^{-3} \mathrm{M}^{-1} \mathrm{~s}^{-1} \quad$ and $k_{\text {glyoxylate }+\mathrm{H}_{2} \mathrm{O}_{2}}=(0.11 \pm 0.01) \mathrm{M}^{-1} \mathrm{~s}^{-1}$ for glyoxylic acid and glyoxylate, respectively. Scheme 3 shows the reaction pathway which occurs analogously to pyruvate. In this case, the formation of formiate is observed during the capillary electrophoresis measurements. Formiate could also be confirmed as the main oxidation product by Tan et al. (2010) and Zhao et al. (2013). Zhao et al. (2013) furthermore propose the additional formation of $\alpha$-hydroxyhydroperoxides ( $\alpha$-HHPs) because the amount of formic acid formed was smaller than the decay of glyoxylic acid.

For glycolic acid and glycolate no kinetic investigations could be undertaken because of the insufficient recovery rate of the anion in the CE. Furthermore, the UV/Vis spectra of the two reactants also do not permit the use of UV / Vis spectroscopy because no wavelength could be identified, where the spectra differ by at least one order of magnitude.

\subsubsection{Aldehydes $+\mathrm{H}_{2} \mathrm{O}_{2}$}

The reactivity of aldehydes towards hydrogen peroxide is very small. The rate constants obtained for glycolaldehyde and glyoxal are $k_{\text {glycolaldehyde }}=(0.04 \pm 0.02) \mathrm{M}^{-1} \mathrm{~s}^{-1}$ and $k_{\text {glyoxal }+\mathrm{H}_{2} \mathrm{O}_{2}}=(1.67 \pm 0.80) \times 10^{-4} \mathrm{M}^{-1} \mathrm{~s}^{-1}$, respectively. Patai and Zabicky (1970) state a rate constant for formaldehyde exposed to $\mathrm{H}_{2} \mathrm{O}_{2}$ of $1.4 \times 10^{-3} \mathrm{M}^{-1} \mathrm{~s}^{-1}$, indicating slow reactions throughout.
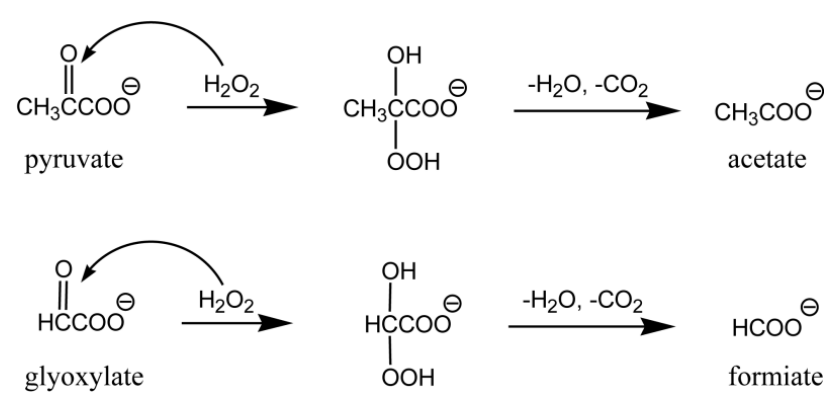

Scheme 3. Reaction mechanism of pyruvate and glyoxylate $+\mathrm{H}_{2} \mathrm{O}_{2}$.

Carlton et al. (2007) suggested the formation of two formic acid molecules in the reaction of glyoxal with $\mathrm{H}_{2} \mathrm{O}_{2}$. These authors propose a rate constant of $1 \mathrm{M}^{-1} \mathrm{~s}^{-1}$ which is about four orders of magnitude larger than in this work. This value was not measured but fitted during their model studies. Zhao et al. (2013) also observed the formation of small amounts of formic acid during the reaction of glyoxal with hydrogen peroxide whereas another product might be hydroxyhydroperoxides (Zhao et al., 2008; Zhao et al. 2012; Huang et al., 2013). The formation of such species was already proposed much earlier by Satterfield and Case (1956).

For the reaction between methylglyoxal and $\mathrm{H}_{2} \mathrm{O}_{2}$ no rate constant could be determined because of the inappropriate UV/Vis spectra of both reactants. The spectra are too similar to extract a wavelength where they differ by at least one order of magnitude. Nevertheless, test measurements were undertaken which indicated a reaction even slower than with glyoxal.

\subsubsection{Unsaturated compounds $+\mathrm{H}_{2} \mathrm{O}_{2}$}

The rate constant for the reaction of methacrolein with $\mathrm{H}_{2} \mathrm{O}_{2}$ was determined to $k_{\mathrm{MACR}}=(7.56 \pm 2.84) \times 10^{-2} \mathrm{M}^{-1} \mathrm{~s}^{-1}$. Zhang et al. (2009) give an upper limit as an estimate of $0.13 \mathrm{M}^{-1} \mathrm{~s}^{-1}$, which is about a factor of 2 larger.

Claeys et al. (2004) propose an acid-catalysed addition of hydrogen peroxide to the molecule forming 2,3-dihydroxymethacrylic acid, whereas Zhao et al. (2013) did not observe this specified product during their 
measurements. Zhao et al. (2013) furthermore confirm the small reactivity of MACR towards $\mathrm{H}_{2} \mathrm{O}_{2}$.

Due to a missing appropriate wavelength where the spectra differ by at least one order of magnitude, the reaction of MVK with $\mathrm{H}_{2} \mathrm{O}_{2}$ could not be investigated kinetically. Nevertheless, Zhao et al. (2013) state that ketones in general are relatively stable against nucleophilic addition.

\subsection{Comparison to model studies}

Table 2 summarises the second-order rate constants measured at $298 \mathrm{~K}$. Apart from the reactions of the unsaturated compounds methacrolein and methyl vinyl ketone with ozone, the investigated monocarboxylic acids and aldehydes show only small absolute rate constants in their reactions with $\mathrm{H}_{2} \mathrm{O}_{2}$ and ozone. The second-order rate constants lie below $3 \mathrm{M}^{-1} \mathrm{~s}^{-1}$.

A comparison with radical reaction rate constants in the aqueous phase reveals a difference of several orders of magnitude since the values are $k_{\mathrm{OH}} \bullet \sim 10^{9} \mathrm{M}^{-1} \mathrm{~s}^{-1}$ and $k_{\mathrm{NO}_{3}} \cdot \sim 10^{7}-10^{8} \mathrm{M}^{-1} \mathrm{~s}^{-1}$, respectively. From that point of view, the examined reactions do not seem to have any influence on the degradation of organics in the global aqueous environmental system. However, not only rate constants are important to be considered to judge the importance of a reaction, but also the concentration of the investigated substances, because first-order conversion rate constants $k_{1 \mathrm{st}}$ are described by the product of rate constant and reactants' concentrations. Therefore, $k_{1 \mathrm{st}}\left[\mathrm{s}^{-1}\right]$ is calculated according to Eq. (2) multiplying the second-order rate constants $\left[\mathrm{M}^{-1} \mathrm{~s}^{-1}\right]$ by the corresponding oxidant concentration $c(\mathrm{X})[\mathrm{M}]$. The non-radical reaction rate constants are taken from the present work, whereas aqueous phase radical reaction rate constants are adopted from Tilgner and Herrmann (2010). Oxidant concentrations were calculated from CAPRAM3.0i. CAPRAM stands for Chemical Aqueous Phase RAdical Mechanism and deals with, e.g., the radical-driven conversion of carbonyls to acids and further acid degradation in tropospheric aqueous systems (Tilgner and Herrmann, 2010). Table 4 summarises maximum concentrations of hydroxyl $\mathrm{OH}$ - and nitrate $\mathrm{NO}_{3}$. radicals as well as $\mathrm{H}_{2} \mathrm{O}_{2}$ and ozone at 20-44 hours reaction time occurring in a polluted (so-called 'urban') cloud droplet. It has to be noted that the aqueous phase concentrations given in Table 4 are maximum concentrations of one simulation day. The comparison between $\mathrm{c}(\mathrm{OH} \cdot)$ and $\mathrm{c}\left(\mathrm{H}_{2} \mathrm{O}_{2}\right)$ shows a difference of 10 orders of magnitude, indicating much larger concentrations of non-radical oxidants than of radicals in an urban aqueous environment.

The calculated first order conversion rate constants are plotted in Fig. 6 (logarithmic scale) over the investigated compounds for each of the four oxidants $\mathrm{H}_{2} \mathrm{O}_{2}, \mathrm{O}_{3}, \mathrm{OH} \cdot$ and $\mathrm{NO}_{3} \cdot$. On the right $\mathrm{y}$ axis, the lifetime in days is plotted according to $\tau=1 / k_{2 \text { nd }}[\mathrm{X}]$.
Table 4. Oxidant concentrations for an urban cloud droplet calculated from CAPRAM3.0i at 20-44 h reaction time (Tilgner and Herrmann, 2010).

\begin{tabular}{ll}
\hline Oxidant X & $c(\mathrm{X}) / \mathrm{M}$ \\
\hline $\mathrm{OH} \bullet$ & $1.0 \times 10^{-14}$ \\
$\mathrm{NO}_{3} \bullet$ & $2.0 \times 10^{-13}$ \\
$\mathrm{H}_{2} \mathrm{O}_{2}$ & $1.0 \times 10^{-4}$ \\
$\mathrm{O}_{3}$ & $2.0 \times 10^{-9}$ \\
\hline
\end{tabular}

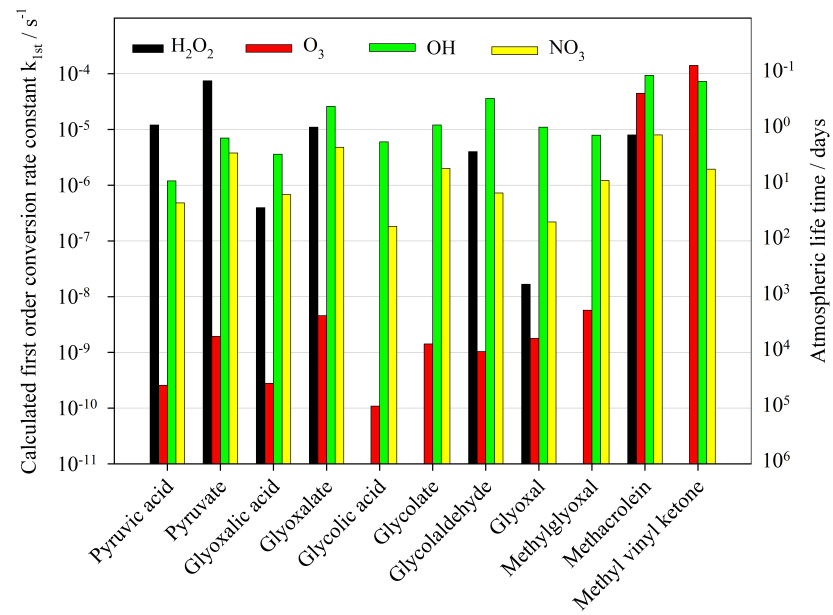

Fig. 6. Intercomparison of the calculated first-order conversion rate constants $k_{1 \mathrm{st}}\left[\mathrm{s}^{-1}\right.$ ] from reactions with $\mathrm{H}_{2} \mathrm{O}_{2}, \mathrm{O}_{3} \mathrm{OH} \bullet$ and $\mathrm{NO}_{3} \bullet$, with the investigated carboxylic acids, aldehydes and unsaturated compounds for an urban cloud droplet.

If $\mathrm{H}_{2} \mathrm{O}_{2}$ first-order conversion rate constants are regarded, only pyruvic acid and pyruvate exceed those of the $\mathrm{OH} \cdot$ radicals. Glyoxylate, glycolaldehyde and glyoxylic acid can also be competitive with $\mathrm{OH}$ - under certain circumstances. Compared with the night-time active nitrate radical, $\mathrm{H}_{2} \mathrm{O}_{2}$ firstorder conversion rate constants show even more importance. From the conducted measurements, it can be pointed pointed out that the $k_{1 \text { st }}$ of glyoxylate and methacrolein with $\mathrm{H}_{2} \mathrm{O}_{2}$ are slightly higher compared to $\mathrm{NO}_{3}$. First-order conversion rate constants of pyruvic acid, pyruvate and glycolaldehyde with $\mathrm{H}_{2} \mathrm{O}_{2}$ exceed those of $\mathrm{NO}_{3}$ • even by one order of magnitude. However, ozone reactions only seem to be competitive with radical reaction first-order conversion rate constants if unsaturated compounds like methacrolein and methyl vinyl ketone are considered.

The aqueous phase concentrations given in Table 4 are taken from CAPRAM3.0i. They are maximum concentrations of one simulation day. The maxima do not occur simultaneously as the oxidants show different diurnal patterns. According to Calvert et al. (2000) and Monks (2005), the highest (gas phase) concentrations of $\mathrm{OH} \cdot$ exist at noon, whereas ozone and $\mathrm{NO}_{3}$. dominate early in the afternoon and during the night, respectively. To accomplish a first comparison, no 
specific time of day was chosen, but maximum concentrations of one entire day.

$\mathrm{H}_{2} \mathrm{O}_{2}$ is highly dependent on the sulphur oxidation capacity in an aqueous environment. Nevertheless, the present considerations are thought to provide a helpful tool to judge on the importance of non-radical reactions on the degradation of organics in the tropospheric aqueous phase.

\section{Conclusions}

Despite the small rate constants determined for the investigated reactions with non-radical oxidants the calculated firstorder conversion rate constants indicate a potential importance of the studied non-radical reactions for the atmosphere. The reason lies in the much larger concentrations of hydrogen peroxide and ozone since these non-radical oxidants are tenfold more prevalent in the tropospheric aqueous phase than radicals like $\mathrm{OH}$. and $\mathrm{NO}_{3}$. Therefore, radical reactions play only a minor role in the degradation of organic substances in cloud droplets and deliquescent particles under certain conditions. Considering non-radical reactions in pre-existing models like CAPRAM dealing to date mainly with the radical-driven reduction of organics (Tilgner and Herrmann, 2010) would change our understanding substantially. The mechanisms occurring during the reaction with non-radical oxidants lead to different products changing the budgets and regimes of these and corresponding compounds. Further investigations and model studies intend to improve the predictability of non-radical reaction rate constants and aim at a better assessment of such reactions in the overall degradation and conversion of organics in the tropospheric aqueous phase.

\section{Supplementary material related to this article is available online at http://www.atmos-chem-phys.net/14/ 4503/2014/acp-14-4503-2014-supplement.pdf.}

Acknowledgements. Luisa Schöne thanks Janine Schindelka, Thomas Schaefer and Christian Weller for continuing support, encouragement, discussion and proofreading of the manuscript. Thanks to Maryna Voyevoda for her help with the laboratory work.

Edited by: A. Laskin

\section{References}

Andreozzi, R., Caprio, V., Insola, A., Marotta, R., and Tufano, V.: The ozonation of pyruvic acid in aqueous solutions catalyzed by suspended and dissolved manganese, Water Res., 32, 1492-1496, doi:10.1016/S0043-1354(97)00367-9, 1998.

Beeby, A., Mohammed, D., and Sodeau, J. R.: Photochemistry and photophysics of glycolaldehyde in solution, J. Am. Chem. Soc., 109, 857-861, 1987.

Betterton, E. A., and Hoffmann, M. R.: Henry's law constants of some environmentally important aldehydes, Environ. Sci. Technol., 22, 1415-1418, doi:10.1021/es00177a004, 1988.

Buxton, G. V., Greenstock, C. L., Helman, W. P., and Ross, A. B.: Critical Review of rate constants for reactions of hydrated electrons, hydrogen atoms and hydroxyl radicals $\left(\cdot \mathrm{OH} / \cdot \mathrm{O}^{-}\right)$in Aqueous Solution, J. Phys. Chem. Ref. Data, 17, 513-886, 1988.

Calvert, J. G.: The mechanisms of atmospheric oxidation of the alkenes, Oxford University Press, 3-22, 2000.

Caprio, V., Insola, A., and Silvestre, A. M.: The Ozonation of Glyoxylic Acid in Aqueous Solution: Chemical Products and Kinetics Evolution, Ozone Sci. Eng., 9, 13-22, doi:10.1080/01919518708552385, 1987.

Carlton, A. G., Turpin, B. J., Lim, H.-J., Altieri, K. E., and Seitzinger, S.: Link between isoprene and secondary organic aerosol (SOA): Pyruvic acid oxidation yields low volatility organic acids in clouds, Geophys. Res. Lett., 33, L06822, doi:10.1029/2005GL025374, 2006.

Carlton, A. G., Turpin, B. J., Altieri, K. E., Seitzinger, S., Reff, A., Lim, H.-J., and Ervens, B.: Atmospheric oxalic acid and SOA production from glyoxal: Results of aqueous photooxidation experiments, Atmos. Environ., 41, 7588-7602, doi:10.1016/j.atmosenv.2007.05.035, 2007.

Charbouillot, T., Gorini, S., Voyard, G., Parazols, M., Brigante, M., Deguillaume, L., Delort, A.-M., and Mailhot, G.: Mechanism of carboxylic acid photooxidation in atmospheric aqueous phase: Formation, fate and reactivity, Atmos. Environ. 56, 1-8, 2012.

Chen, Z. M., Wang, H. L., Zhu, L. H., Wang, C. X., Jie, C. Y., and Hua, W.: Aqueous-phase ozonolysis of methacrolein and methyl vinyl ketone: a potentially important source of atmospheric aqueous oxidants, Atmos. Chem. Phys., 8, 2255-2265, doi:10.5194/acp-8-2255-2008, 2008.

Claeys, M., Wang, W., Ion, A. C., Kourtchev, I., Gelencsér, A., and Maenhaut, W.: Formation of secondary organic aerosols from isoprene and its gas-phase oxidation products through reaction with hydrogen peroxide, Atmos. Environ., 38, 4093-4098, doi:10.1016/j.atmosenv.2004.06.001, 2004.

Collett Jr., J. L., Daube Jr., B. C., Gunz, D., and Hoffmann, M. R.: Intensive studies of Sierra Nevada cloudwater chemistry and its relationship to precursor aerosol and gas concentrations, Atmos. Environ. A General Topics, 24, 1741-1757, 1990.

Dean, J. A., and Lange, N. A.: Lange's handbook of chemistry, McGraw-Hill, 4.41-4.53, 1992.

Ervens, B., Feingold, G., Frost, G. J., and Kreidenweis, S. M.: A modeling study of aqueous production of dicarboxylic acids: 1. Chemical pathways and speciated organic mass production, J. Geophys. Res. Atmos., 109, D15205, doi:10.1029/2003JD004387, 2004.

Ervens, B. and Volkamer, R.: Glyoxal processing by aerosol multiphase chemistry: towards a kinetic modeling framework of secondary organic aerosol formation in aqueous particles, Atmos. 
Chem. Phys., 10, 8219-8244, doi:10.5194/acp-10-8219-2010, 2010.

Galloway, M. M., Loza, C. L., Chhabra, P. S., Chan, A. W. H., Yee, L. D., Seinfeld, J. H., and Keutsch, F. N.: Analysis of photochemical and dark glyoxal uptake: Implications for SOA formation, Geophys. Res. Lett., 38, L17811, doi:10.1029/2011GL048514, 2011.

Guenther, A., Karl, T., Harley, P., Wiedinmyer, C., Palmer, P. I., and Geron, C.: Estimates of global terrestrial isoprene emissions using MEGAN (Model of Emissions of Gases and Aerosols from Nature), Atmos. Chem. Phys., 6, 3181-3210, doi:10.5194/acp-63181-2006, 2006.

Guzmán, M. I., Colussi, A. J., and Hoffmann, M. R.: Photoinduced Oligomerization of Aqueous Pyruvic Acid, J. Phys. Chem. A 110, 3619-3626, 2006.

Hart, E. J., Sehested, K., and Holoman, J.: Molar absorptivities of ultraviolet and visible bands of ozone in aqueous solutions, Anal. Chem., 55, 46-49, doi:10.1021/ac00252a015, 1983.

Herrmann, H., Hoffmann, D., Schaefer, T., Bräuer, P., and Tilgner, A.: Tropospheric Aqueous-Phase Free-Radical Chemistry: Radical Sources, Spectra, Reaction Kinetics and Prediction Tools, Europ. J. Chem. Phys. Phys. Chem., 11, 3796-3822, 2010.

Hoefnagel, A. J., Peters, J. A., and van Bekkum, H.: Metal ion catalysis in the hydroxyalkylation of phenol with glyoxylic acid, Recueil des Travaux Chimiques des Pays-Bas, 107, 242-247, 1988.

Hoigné, J. and Bader, H.: The role of hydroxyl radical reactions in ozonation processes in aqueous solutions, Water Res., 10, 377386, doi:10.1016/0043-1354(76)90055-5, 1976.

Hoigné, J. and Bader, H.: Rate constants of reactions of ozone with organic and inorganic compounds in water - I: Non-dissociating organic compounds, Water Res., 17, 173-183, doi:10.1016/00431354(83)90098-2, 1983a.

Hoigné, J. and Bader, H.: Rate constants of reactions of ozone with organic and inorganic compounds in water - II: Dissociating organic compounds, Water Res., 17, 185-194, doi:10.1016/00431354(83)90099-4, 1983b.

Hoigné, J., Bader, H., Haag, W. R., and Staehelin, J.: Rate constants of reactions of ozone with organic and inorganic compounds in water - III. Inorganic compounds and radicals, Water Res., 19, 993-1004, doi:10.1016/0043-1354(85)90368-9, 1985.

Holen, A. K., Kleppe, P. J., and Moe, S. T.: Reaction of products from ozonation of dissolved carbohydrates, http://www.chemeng.ntnu.no/research/paper/Publications/1998/ ipbc98-akh_pjk_stm.pdf, 1998.

Huang, D., Chen, Z. M., Zhao, Y., and Liang, H.: Newly observed peroxides and the water effect on the formation and removal of hydroxyalkyl hydroperoxides in the ozonolysis of isoprene, Atmos. Chem. Phys., 13, 5671-5683, doi:10.5194/acp-13-56712013, 2013

Ip, H. S. S., Huang, X. H. H., and Yu, J. Z.: Effective Henry's law constants of glyoxal, glyoxylic acid, and glycolic acid, Geophys. Res. Lett., 36, L01802, doi:10.1029/2008gl036212, 2009.

Lim, Y. B., Tan, Y., and Turpin, B. J.: Chemical insights, explicit chemistry, and yields of secondary organic aerosol from $\mathrm{OH}$ radical oxidation of methylglyoxal and glyoxal in the aqueous phase, Atmos. Chem. Phys., 13, 8651-8667, doi:10.5194/acp-13-86512013, 2013.
Liu, Z., Wu, L. Y., Wang, T. H., Ge, M. F., and Wang, W. G.: Uptake of Methacrolein into Aqueous Solutions of Sulfuric Acid and Hydrogen Peroxide, J. Phys. Chem. A 116, 437-442, 2012.

Matsumoto, K., Kawai, S., and Igawa, M.: Dominant factors controlling concentrations of aldehydes in rain, fog, dew water, and in the gas phase, Atmos. Environ., 39, 7321-7329, 2005.

Monks, P. S.: Gas-phase radical chemistry in the troposphere, Chem. Soc. Rev., 34, 376-395, doi:10.1039/b307982c, 2005.

Munger, J. W., Collett Jr., J., Daube Jr, B., and Hoffmann, M. R.: Fogwater chemistry at Riverside, California, Atmos. Environ. B. Urban Atmos., 24, 185-205, 1990.

Munger, J. W., Jacob, D. J., Daube, B. C., Horowitz, L. W., Keene, W. C., and Heikes, B. G.: Formaldehyde, glyoxal, and methylglyoxal in air and cloudwater at a rural mountain site in central Virginia, J. Geophys. Res. Atmos., 100, 9325-9333, 1995.

Myriokefalitakis, S., Tsigaridis, K., Mihalopoulos, N., Sciare, J., Nenes, A., Kawamura, K., Segers, A., and Kanakidou, M.: Incloud oxalate formation in the global troposphere: a 3-D modeling study, Atmos. Chem. Phys., 11, 5761-5782, doi:10.5194/acp11-5761-2011, 2011

Ogura, Y.: Catalase activity at high concentration of hydrogen peroxide, Arch. Biochem. Biophys., 57, 288-300, 1955.

Patai, S. and Zabicky, J.: The chemistry of the carbonyl group, Bd. 2, Interscience Publishers, 1970.

Perri, M. J., Seitzinger, S. P., and Turpin, B. J.: Secondary organic aerosol production from aqueous photooxidation of glycolaldehyde: Laboratory experiments, Atmos. Environ. 43, 1487-1497, 2008.

Satterfield, C. N. and Case, L. C.: Reaction of Aldehyde and Hydrogen Peroxide in Aqueous Solution, Ind. Eng. Chem., 46, 998 1001, doi:10.1021/ie50533a049, 1954.

Sehested, K., Holcman, J., Bjergbakke, E., and Hart, E. J.: A pulse radiolytic study of the reaction hydroxyl + ozone in aqueous medium, The J. Phys. Chem., 88, 4144-4147, doi:10.1021/j150662a058, 1984.

Sehested, K., Corfitzen, H., Holcman, J., Fischer, C. H., and Hart, E. J.: The primary reaction in the decomposition of ozone in acidic aqueous solutions, Environ. Sci. Technol., 25, 1589-1596, doi:10.1021/es00021a010, 1991.

Sharkey, T. D., Wiberley, A. E., and Donohue, A. R.: Isoprene emission from plants: Why and how, Ann. Botany, 101, 5-18, 2008.

Staehelin, J. and Hoigne, J.: Decomposition of ozone in water: rate of initiation by hydroxide ions and hydrogen peroxide, Environ Sci. Technol., 16, 676-681, doi:10.1021/es00104a009, 1982.

Stefan, M. I. and Bolton, J. R.: Reinvestigation of the Acetone Degradation Mechanism in Dilute Aqueous Solution by the UV/ $\mathrm{H}_{2} \mathrm{O}_{2}$ Process, Environ. Sci. Technol., 33, 870-873, doi:10.1021/es9808548, 1999.

Tan, Y., Carlton, A. G., Seitzinger, S. P., and Turpin, B. J.: SOA from methylglyoxal in clouds and wet aerosols: Measurement and prediction of key products, Atmos. Environ., 44, 5218-5226, doi:10.1016/j.atmosenv.2010.08.045, 2010.

Tilgner, A. and Herrmann, H.: Radical-driven carbonyl-to-acid conversion and acid degradation in tropospheric aqueous systems studied by CAPRAM, Atmos. Environ., 44, 5415-5422, doi:10.1016/j.atmosenv.2010.07.050, 2010.

van Pinxteren, D., Plewka, A., Hoffmann, D., Müller, K., Kramberger, H., Svrcina, B., Bachmann, K., Jaeschke, W., Mertes, S., Collett, J. L., and Herrmann, H.: Schmücke hill cap cloud and 
valley stations aerosol characterisation during FEBUKO (II): Organic compounds, Atmos. Environ. 39, 4305-4320, 2005.

von Sonntag, C. and Schuchmann, H.-P.: The Elucidation of Peroxyl Radical Reactions in Aqueous Solution with the Help of Radiation-Chemical Methods, Angew. Chemie Int. Ed. Eng., 30, 1229-1253, doi:10.1002/anie.199112291, 1991.

von Sonntag, C. and Schuchmann, H. P.: The chemistry of free radicals: peroxy radicals in aqueous solutions, Peroxyl Radicals, edited by: Alfassi, Z. B. Wiley, Chichester, UK, 173-214, 1997.

Voukides, A. C., Konrad, K. M., and Johnson, R. P.: Competing mechanistic channels in the oxidation of aldehydes by ozone, J. Rrgan. Chem., 74, 2108-2113, 2009.

Yao Liu, El Haddad, I., Scarfogliero, M., Nieto-Gligorovski, L., Temime-Roussel, B., Quivet, E., Marchand, N., Picquet-Varrault, B., and Monod, A.: In-cloud processes of methacrolein under simulated conditions - Part 1: Aqueous phase photooxidation, Atmos. Chem. Phys., 9, 5093-5105, doi:10.5194/acp-9-50932009, 2009.

Zhang, Q., Jimenez, J. L., Canagaratna, M. R., Allan, J. D., Coe, H., Ulbrich, I., Alfarra, M. R., Takami, A., Middlebrook, A. M., Sun, Y. L., Dzepina, K., Dunlea, E., Docherty, K., DeCarlo, P. F., Salcedo, D., Onasch, T., Jayne, J. T., Miyoshi, T., Shimono, A., Hatakeyama, S., Takegawa, N., Kondo, Y., Schneider, J., Drewnick, F., Borrmann, S., Weimer, S., Demerjian, K., Williams, P., Bower, K., Bahreini, R., Cottrell, L., Griffin, R. J., Rautiainen, J., Sun, J. Y., Zhang, Y. M., and Worsnop, D. R.: Ubiquity and dominance of oxygenated species in organic aerosols in anthropogenically-influenced Northern Hemisphere midlatitudes, Geophys. Res. Lett., 34, L13801, doi:10.1029/2007GL029979, 2007.
Zhang, X., Chen, Z. M., Wang, H. L., He, S. Z., and Huang, D. M.: An important pathway for ozonolysis of alpha-pinene and beta-pinene in aqueous phase and its atmospheric implications, Atmos. Environ., 43, 4465-4471, 2009.

Zhao, R., Lee, A. K. Y., and Abbatt, J. P. D.: Investigation of Aqueous-Phase Photooxidation of Glyoxal and Methylglyoxal by Aerosol Chemical Ionization Mass Spectrometry: Observation of Hydroxyhydroperoxide Formation, The J. Phys. Chem. A, 116, 6253-6263, doi:10.1021/jp211528d, 2012.

Zhao, R., Lee, A. K. Y., Soong, R., Simpson, A. J., and Abbatt, J. P. D.: Formation of aqueous-phase ?-hydroxyhydroperoxides (?HHP): potential atmospheric impacts, Atmos. Chem. Phys., 13, 5857-5872, doi:10.5194/acp-13-5857-2013, 2013.

Zhao, X., Zhang, T., Zhou, Y., and Liu, D.: Preparation of Peracetic Acid from Acetic Acid and Hydrogen Peroxide: Experimentation and Modeling, Chin. J. Proc. Eng., 8, 35-41, 2008. 